\title{
Contemos mellhores histórias no caos: Grossberg e a análise conjuntural da vitória de Trump em 2016
}

\author{
Let us tell better stories in chaos: Grossberg and the conjunctural analysis of \\ Trump's victory
}

\section{Thiago Ferreira}

Doutor pelo Programa de Pós Graduação em Comunicação e Cultura Contemporâneas da Universidade Federal da Bahia (Póscom/UFBA), com período de doutorado-sanduíche na Sorbonne-Nouvelle (Paris 3). Pesquisador associado ao Centro de Pesquisa em Estudos Culturais e Transformações na Comunicação (TRACC/UFBA).

Submetido em 21 de Junho de 2019 Aceito em 14 de Setembro de 2020

\section{RESUMO}

A presente resenha tem como objetivo discutir o livro Under the cover of the Chaos: Trump and the Battle for the American Right, escrito por Lawrence Grossberg, professor do departamento de Comunicação da Universidade da Carolina do Norte. Nele, o autor realiza uma análise conjuntural dos Estados Unidos partindo da vitória de Trump, evidenciando afetos e disputas que se articulam a várias formações de direita naquele país. Por fim, Grossberg propõe que contemos melhores histórias, explicitando a existência de distintas temporalidades em torno dessas direitas e a necessidade de uma ação política que considere o lugar da imaginação.

Pallavras-chave: Afetos; Conjuntura; Contextos; Trump.

\section{ABSTRACT}

This review aims to discuss the book Under the cover of the Chaos: Trump and the Battle for the American Right, written by Lawrence Grossberg, professor at the Department of Communication at the University of North Carolina. In this book, the author makes a conjunctural analysis of the United States starting from the victory of Trump, evidencing affects and disputes that are articulated to several formations of the right-wing in that country. Finally, Grossberg claims that we should tell better stories, explaining the 
existence of different temporalities around these right wings and the need for a political action that considers the place of the imagination.

Keywords: Affects; Conjuncture; Contexts; Trump.

\section{RÉSUMÉ}

Cette revue a pour objectif de discuter du livre Under the cover of the Chaos: Trump and the Battle for the American Right, écrit par Lawrence Grossberg, professeur au département de communication de l'Université de Caroline du Nord. Dans ce livre, l'auteur fait une analyse conjoncturelle des États-Unis à partir de la victoire de Trump, mettant en évidence des affects et des différends qui s'articulent autour de plusieurs formations de droit dans ce pays. Enfin, Grossberg propose de raconter des meilleures histoires, en expliquant l'existence de différentes temporalités autour de ces droits et la nécessité d'une action politique tenant compte de la place de l'imaginaire.

MOTS-CLÉS: Affects; Conjoncture; Contextes; Trump.

Em seu livro mais recente, Under the cover of the Chaos: Trump and the Battle for the American Right, publicado em 2018, e ainda sem tradução para o português, Lawrence Grossberg, professor do departamento de Comunicação da Universidade da Carolina do Norte e um dos expoentes dos estudos culturais estadunidenses, realiza uma análise conjuntural do seu país a partir da vitória de Donald Trump como presidente. Para ele, esse resultado eleitoral se relaciona a várias formações de direitas e discursos do caos e do medo nos Estados Unidos que são propagados em diferentes espaços, incluídos meios de comunicação.

Nesse mesmo livro, Grossberg defende que mudar o estado das coisas passa por contar melhores histórias, utilizando linguagens que cheguem às pessoas, onde elas estejam. A partir dessa premissa, ele aprofunda argumentos elaborados em duas das suas obras anteriores - Cultural Studies in the Future Tense (2010) e We gotta get out of this place (1992) -, explicitando a centralidade que a política possui para compreensão da vida cotidiana na modernidade e como o medo, o caos e a desesperança são elementos que permitem compreender a política nos Estados Unidos. Ele cita diversos 
produtos comunicacionais, entre eles, Robocop, Qarth (cidade da série da HBO Game of thrones) e $O$ conto da $\mathrm{aia}^{1}$, que deixam ver como esses elementos culturais se espraiam.

Os argumentos de Grossberg giram em torno de três eixos: 1) a necessidade de diferenciar as direitas que se articulam em torno de Trump; 2) a discussão de equívocos da esquerda; 3) uma análise de diversas temporalidades que permitem compreender o momento pelo qual passa aquele país - permitindo alguns insights em relação ao Brasil. Uma das semelhanças: ele afirma que a divisão das esquerdas é desanimadora e que o retorno a um essencialismo daqueles que defendem as políticas de identidades acarreta em uma "estratégia vitimista", que acaba sendo apropriada por parte da direita na defesa dos "homens brancos". Apesar disso, ele recusa que as políticas identitárias sejam responsabilizadas pelos problemas das esquerdas, sendo necessária a construção de uma estratégia progressista popular que articule injustiças culturais - racismo, sexismo e homofobia - e questões de desigualdade econômica e democracia política (GROSSBERG, 2018, p. 22).

A partir dessas compreensões, as esquerdas e aqueles que se opõem a Trump devem criar novas estratégias, partindo do ponto inicial de que o "caos é o terreno produtivo e estratégico para, pelo menos, algumas das trajetórias e projetos em ação hoje"23 (GROSSBERG, 2018, p. 4). Há alterações "nas placas tectônicas" que definem a modernidade. 0 caos seria, portanto, uma estratégia e um objetivo políticos, sendo a imaginação um importante lugar para as disputas políticas e afetivas. Trump soube, de acordo com Grossberg, manejar um diagnóstico distópico sobre a realidade e oferecer promessas utópicas. Compreendemos, portanto, que distopias e utopias dependem daqueles para os quais elas se endereçam. Tornar a América grande de novo ${ }^{4}$ é uma

\footnotetext{
${ }^{1}$ Citamos como exemplo o livro $O$ conto da aia (The handmaid's tale), da canadense Margaret Atwood, publicado na década de 1980. 0 livro aborda um futuro distópico em que o governo dos Estados Unidos é assumido por uma organização política fundamentalista. Em 2017, a empresa de streaming Hulu lançou uma série inspirada no livro.

${ }^{2}$ No original: "[...] chaos is the productive and strategic ground for at least some of the political trajectories and projects at work today" (GROSSBERG, 2018, p. 4).

${ }^{3}$ Todas as traduções nessa resenha são de nossa autoria.

4 "Make America great again" foi o slogan usado por Trump em sua campanha.
}

Dossiê 0 Pensamento Ecológico - $\underline{\text { https://revistaecopos.eco.ufrj.br/ }}$

ISSN 2175-8689 - v. 23, n. 2, 2020

DOI: 10.29146/eco-pos.v23i2.27286 
utopia com apelo junto a um grande número de estadunidenses com quem Trump dialoga.

Grossberg afirma ainda que é preciso relembrar que havia um conservadorismo em outros momentos daquele país, como no governo Bush. Entretanto, há alterações, em anos recentes, evidenciadas nas disputas empreendidas pelo Tea Party e pelos conservadores em torno do partido Republicano. Ele identifica cinco formas principais do que ele classifica como políticas reacionárias nos EUA de hoje - supremacistas brancos, populistas do Tea Party, contraculturalistas de direita, intelectuais neoreacionários e intelectuais "trumpistas" (GROSSBERG, 2018, p. 8) -, devendo cada uma delas ser compreendida em suas especificidades, ainda que deem naquilo que ele vai caracterizar como uma "contra-modernidade reacionária". Para ele, por exemplo, nem todas essas formações políticas são modernistas anti-liberais, como a "Nova Direita", "mas sim anti-modernistas ou mesmo pré-modernistas (idem)"5. A vitória de Trump faz esses grupos entrarem no bloco de poder, mas também os faz disputarem entre si, com a Nova Direita tendo que assumir posições ainda mais reacionárias.

A observação do quadro descrito acima faz Grossberg defender que a política deva ser discutida em termos afetivos. Afeto é um conceito central para o autor, e ele o define como "uma dimensão essencial ou ingrediente das desordens da experiência humana [...] produto contingente de eventos, contradições e lutas humanas e nãohumanas" (GROSSBERG, 2018, p. 10)6 , variando no espaço-tempo. "Afeto é sempre constituído no espaço entre individualidade e sociabilidade, entre consciência e materialidade, entre o cognoscível e o ainda-não-articulado. Afeto engloba uma variedade de formas pelas quais "sentimos" o mundo na nossa experiência" (idem, p. $11)^{7}$.

\footnotetext{
${ }^{5}$ No original: "They are not merely anti-liberal modernists (the "New Right"), but anti-modernists or even pre-modernists" (idem, p. 8).

${ }^{6}$ No original: "[...] an essential dimension or ingredient of the messinesss of human experience [...] contingent product of human and non-human events, contradictions and struggles" (ibidem, p. 10).

${ }^{7}$ No original: "[...] affect is always constituted in the space between individuality and sociality, between consciousness and materiality, between the knowable and the not-yet-articulated. Affect encompasses a variety of ways in which we "feel" the world in our experience [...]" (GROSSBERG, 2018, p. 11).
}

Dossiê 0 Pensamento Ecológico - $\underline{\text { https://revistaecopos.eco.ufrj.br/ }}$

ISSN 2175-8689 - v. 23, n. 2, 2020

DOI: 10.29146/eco-pos.v23i2.27286 
Um desdobramento importante na discussão que Grossberg faz dos afetos é a formulação do conceito de paisagens afetivas: condições de possibilidade, contextos profundos através dos quais as pessoas podem experienciar determinados processos e fenômenos. Não são um pano de fundo, mas sim expressões ativas que determinam as possibilidades, ritmos e padrões da experiência social (GROSSBERG, 2018, p. 91). De acordo com Grossberg, os contextos são produzidos pela análise conjuntural, podendo abranger diversas paisagens afetivas.

Observar os contextos dessa maneira parece-nos uma mudança importante nas discussões que empreendemos na área da comunicação, deixando de pensá-los como meros retratos ou panos de fundo e passando a pensá-los como resultados dos próprios processos analíticos. Além disso, ter a própria conjuntura e a produção de contextos como os lugares de análise, e não os produtos midiáticos - ainda que eles não sejam descartados como lugares de olhada - é outro desdobramento provocado pela obra de Grossberg não apenas para os estudos culturais dos Estados Unidos. Compreensões que partem do compromisso político do autor para alterar o estado das coisas.

É discutindo a paisagem afetiva nos Estados Unidos na relação com as várias formações de direitas que o autor compreende que a que possui dominância, naquele país, caracteriza-se por um niilismo passivo (idem, p. 11), em que o desânimo perante o mundo faz com que se deixe de agir no sentido de transformá-lo. Grossberg relaciona ainda as suas discussões sobre política e afeto ao conceito de estrutura de sentimento (WILLIAMS, 1979) ${ }^{8}$. Para ele, uma mesma paisagem afetiva pode abranger distintas estruturas de sentimento. No caso analisado pelo autor, há quatro estruturas de sentimento atuando no niilismo passivo: autonomia afetiva, ansiedade, narcisismo e alienação temporal. A primeira descreve o sentimento de separação entre o que interessa de fato e aquilo que tenha um valor ou conteúdo real. Vivemos em uma era de um exagero afetivo, em que tudo é visto de maneira exclamativa (GROSSBERG, 2018, p.

\footnotetext{
${ }^{8}$ Para mais argumentos em torno da importância do conceito de estrutura de sentimento, ler Gomes (2011).
}

\section{Dossiê O Pensamento Ecológico - https://revistaecopos.eco.ufrj.br/}

ISSN 2175-8689 - v. 23, n. 2, 2020

DOI: 10.29146/eco-pos.v23i2.27286 
95), dando em uma hiperinflação que pode ocasionar fundamentalismo e fanatismo, haja vista que o outro lado - aquilo que não merece minha atenção - é sempre um problema.

A ansiedade como estrutura de sentimento evidencia o fato de que tudo está em iminência de uma crise. Ainda que seja sempre experienciada no presente, a ansiedade é sempre "uma futuridade" (GROSSBERG, 2018, p. 99). Essa ansiedade onipresente resulta em hiperatividade, na sensação de ter sempre algo para fazer. 0 narcisismo é demonstrado em uma personalização radical de tudo, no redesenho dos limites entre o público e o privado, com o crescimento da revelação do eu em público. Grossberg afirma que essa não é uma nova estrutura de sentimento, mas que há especificidades, como o sentimento crescente da uma onipotência pessoal, que se relaciona às estruturas de sentimento anteriores. Isso acarreta em um problema em torno dos discursos de que devemos mudar a nós mesmos e não ao mundo. Quando falhamos, portanto, continuamos sendo responsáveis pela derrota; em vez de responsabilizarmos aspectos mais abrangentes de estruturas sociais.

E, por fim, a alienação temporal que é "a nostalgia pela própria (im)possibilidade de um passado e futuro, uma melancolia no futuro (progressivo) perfeito ${ }^{9}$, deixando-nos presos em um presente que parou"10 (GROSSBERG, 2018, p. 106). A consequência disso é um tipo de amnésia geral sobre o passado, que se vincula, segundo Grossberg, à "espetacularização do trivial", e a ausência de qualquer responsabilidade sobre o futuro. Somos, portanto, estranhos em uma temporalidade estranha. "É uma alienação do próprio tempo, um tempo cada vez mais fora do comum, fora do lugar, fora do tempo. Esta é uma alienação afetiva da temporalidade da própria experiência no tempo, como se, de alguma forma, o próprio tempo tivesse dado errado" (idem, p. 107) ${ }^{11}$.

\footnotetext{
${ }^{9}$ Grossberg faz referência aqui ao tempo verbal future perfect. Tempo utilizado na descrição de ações que estarão concluídas em algum momento futuro.

${ }^{10}$ No original: "It is nostalgia for the very (im)possibility of a past and future, a melancholia in the future perfect (progressive) tense, leaving us stuck in a present that has stalled" (GROSSBERG, 2018, p. 106).

${ }^{11}$ No original: "It is an alienation of time itself, a time that is increasingly out-of-joint, out of place, out of time. This is an affective alienation from the temporality of one's own experience in time, as if, somehow, time itself has gone wrong" (idem, p. 107).
}

Dossiê 0 Pensamento Ecológico - $\underline{\text { https://revistaecopos.eco.ufrj.br/ }}$

ISSN 2175-8689 - v. 23, n. 2, 2020

DOI: 10.29146/eco-pos.v23i2.27286 
Grossberg conclui o livro apontando recomendações para progressistas e pessoas de esquerda nos Estados Unidos - e, arriscaríamos dizer, no mundo - em torno da necessidade de criticar as corporações que, segundo ele, são vistas como isentas de problemas, em detrimento de uma visão deteriorada do Estado. Diagnóstico que não o impossibilita de criticar a relação entre políticos e Estado e a urgência de reinventá-lo, e de defender que prestemos atenção ao que Trump e figuras políticas semelhantes a ele fazem, sem abrir mão de pensar outros afetos e temporalidades, de formular estratégias políticas de longo prazo, apostando em unidades-na-diferença e retomando nossa capacidade de imaginar brechas e outros futuros possíveis. Para ele, o fascismo de nossa era é considerar que a imaginação está morta.

\section{Referências bibliográficas}

Livro resenhado: GROSSBERG, Lawrence. Under the cover of chaos: Trump and the Battle for the American Right. 2018. Londres: Pluto Press.

GOMES, Itania. Raymond Williams e a hipótese cultural da Estrutura de Sentimento. In: JANOTTI, Jr., Jéder; GOMES, Itania Maria Mota. Comunicação e Estudos Culturais. Salvador: EDUFBA, 2011.

GROSSBERG, Lawrence. Cultural Studies in the Future Tense. Durham: Duke University Press, 2010.

GROSSBERG, Lawrence. We Gotta Get Out of This Place: Popular Conservatism and Postmodern Culture. Londres: Routledge, 1992.

WILLIAMS, Raymond. Marxismo e Literatura (Trad. de Waltensir Dutra). Rio de Janeiro: Jorge Zahar, [1971]1979. 